\title{
BMJ Open Early real-world evidence of persistence on oral anticoagulants for stroke prevention in non-valvular atrial fibrillation: a cohort study in UK primary care
}

\author{
Michelle E Johnson, ${ }^{1}$ Cinira Lefèvre, ${ }^{2}$ Shuk-Li Collings, ${ }^{1}$ David Evans, ${ }^{2}$ \\ Sebastian Kloss, ${ }^{3}$ Essra Ridha, ${ }^{4}$ Andrew Maguire ${ }^{1}$
}

To cite: Johnson ME, Lefèvre $\mathrm{C}$, Collings $\mathrm{S}$, et al. Early real-world evidence of persistence on oral anticoagulants for stroke prevention in non-valvular atrial fibrillation: a cohort study in UK primary care. BMJ Open 2016;6:e011471. doi:10.1136/bmjopen-2016011471

- Prepublication history for this paper is available online. To view these files please visit the journal online (http://dx.doi.org/10.1136/ bmjopen-2016-011471).

Received 11 February 2016 Revised 7 July 2016 Accepted 18 August 2016

CrossMark

\section{${ }^{1}$ OXON Epidemiology, London, UK \\ ${ }^{2}$ Department of Worldwide Health Economics \& Outcomes Research, Bristol- Myers Squibb, Paris, France ${ }^{3}$ Pfizer, Berlin, Germany ${ }^{4}$ Medical Department UK, Bristol-Myers Squibb, London, UK}

Correspondence to Michelle E Johnson; michelle.johnson@oxonepi.com

\section{ABSTRACT}

Objectives: To examine the characteristics and persistence in patients newly initiated with oral anticoagulants (OACs) for stroke prevention in nonvalvular atrial fibrillation (NVAF).

Design: Cohort study in Clinical Practice Research Datalink.

Setting: UK primary care.

Participants: 15242 patients with NVAF newly prescribed apixaban, rivaroxaban, dabigatran or vitamin $\mathrm{K}$ antagonists (VKAs) between 1 December 2012 and 31 October 2014. 13089 patients were OAC naïve.

Outcome measures: Patient characteristics and risk of non-persistence compared to apixaban using Cox regression models over the entire follow-up and using a time-partitioned approach to handle non-proportional hazards.

Results: Among the OAC naïve patients, VKAs were most common $(78.1 \%, \mathrm{n}=10218)$, followed by rivaroxaban $(12.1 \%, \mathrm{n}=1589)$, dabigatran $(5.7 \%$, $\mathrm{n}=741)$ and apixaban $(4.1 \%, \mathrm{n}=541)$. High baseline stroke risk $\left(\mathrm{CHA}_{2} \mathrm{DS}_{2} \mathrm{VASC} \geq 2\right)$ ranged from $80.2 \%$ (dabigatran) to $88.4 \%$ (apixaban and rivaroxaban). History of stroke and bleeding was the highest among apixaban (23.7\% and $31.6 \%)$ and lowest among VKA patients (15.9\% and $27.5 \%)$. Across the entire followup period, adjusting for differences in characteristics, there was no evidence of a difference in non-persistence between VKA and apixaban (HR $0.92(95 \% \mathrm{Cl} 0.68$ to 1.23)). Non-persistence was higher with dabigatran (HR 1.67 (1.20 to 2.32)) and rivaroxaban (HR 1.41 (1.02 to 1.93)) than apixaban. Using the partitioned approach, non-persistence was lower with VKA (HR 0.33 (0.22 to $0.48)$ ), and higher with dabigatran (HR 1.65 (1.08 to 2.52)) compared to apixaban in the first 2 months of follow-up. After 2 months, non-persistence was higher with VKA (HR 1.70 (1.08 to 2.66)) and dabigatran (HR 2.10 (1.30 to 3.41)). Pooling OAC naïve and experienced patients, non-persistence was also higher with rivaroxaban compared to apixaban after 2 months of follow-up (HR 1.69 (1.19 to 2.39)).

Conclusions: Observed differential prescribing of OACs can result in channelling bias in comparative

\section{Strengths and limitations of this study}

- Owing to its relatively recent licencing, little is known on the use of and persistence with the novel oral anticoagulant, apixaban, for stroke prevention in non-valvular atrial fibrillation.

- This study uses a large, representative, wellvalidated UK primary care database to examine patient characteristics and treatment persistence with oral anticoagulants.

- Furthermore, the use of a large database allows comparison of persistence with other oral anticoagulants to apixaban.

- Electronic health records can contain considerable levels of missing data, may lack confounders appropriate for this study and is open to misclassification bias.

effectiveness research. Persistence patterns changed over follow-up time, but there are indications of improved persistence rates with apixaban over other OACs in the UK. A larger study with longer follow-up is needed to corroborate findings. This study is registered on ClinicalTrials.gov (NCT02488421).

\section{INTRODUCTION}

\section{Background}

Atrial fibrillation (AF) is the most commonly sustained arrhythmia with an incidence of 1.7 per 1000 person-years in the UK. ${ }^{1}$ More commonly affecting males than females and those in older age, ${ }^{2} \mathrm{AF}$ can reduce quality of life and mental health, and is associated with increased risk of morbidity and mortality. ${ }^{4}$ Strokes due to AF tend to be ischaemic strokes-one in five ischaemic strokes can be attributed to $\mathrm{AF}^{6}$ This high risk and potentially devastating impact of a stroke demands preventative treatment to be a vital component of care in patients with $\mathrm{AF}$. 
Traditionally, vitamin $\mathrm{K}$ antagonists (VKAs) such as warfarin have been used as anticoagulation therapy for stroke prevention in AF; however, these drugs have a narrow therapeutic window that forces regular monitoring and dietary restrictions. ${ }^{7}$ Consequently it is difficult to maintain anticoagulation with VKA therapy within the therapeutic range, ${ }^{8}$ leading to a significant risk of stroke if insufficiently anticoagulated. Studies have found poor persistence with VKA in AF; over a quarter of users stop treatment within a year of initiation. ${ }^{9-11}$

In recent years, novel oral anticoagulants (NOACs) have been developed, changing the landscape of stroke prevention in non-valvular AF (NVAF). Currently (as of September 2015), the NOACs licenced for stroke prevention in NVAF in the UK are dabigatran, rivaroxaban, apixaban and edoxaban. ${ }^{12} 13$ These drugs were developed to be simpler to use by taking away the need for regular monitoring, and to have lesser side effects. ${ }^{14}{ }^{15}$ However, all OACs have the potential for causing adverse bleeding events, which is a common reason for stopping anticoagulant treatment. ${ }^{16}{ }^{17}$ Clinical trials have shown promising results in terms of the safety of NOACs relative to VKAsthe ARISTOTLE trial found lower bleeding and mortality rates with apixaban over warfarin, ${ }^{18}$ and the RE-LY trial found low dose dabigatran was associated with lower rates of major haemorrhage compared to warfarin. ${ }^{19}$

An understanding of persistence can provide insight into the tolerability, safety and effectiveness of a drug. However, there is little real-world evidence on the comparative persistence of OACs, particularly on apixaban due to its relatively recent licencing for this indication. Early findings from a US claims data study suggest improved persistence with apixaban over rivaroxaban, dabigatran and VKA, ${ }^{20}$ which has been somewhat supported by a regional claims data study in Sweden, except that they found persistence to be similar between VKA and apixaban. ${ }^{21}$ Other real-world studies of persistence have compared VKA with a mixed treatment group of patients on any NOAC, which can have limited interpretability. ${ }^{22}$

Real-world data studies are key to understanding drug persistence outside clinical trials. Clinical trial settings are heavily monitored and participants unlikely to be reflective of those who are prescribed the drug in clinical practice, potentially inflating observed persistence. Real-world data can demonstrate drug use in a natural environment with clinical factors and personal preferences playing a part in how well the drug is adhered to. Additionally, real-world data studies can provide an understanding, via assessment of patient characteristics, of whether we could expect differences in outcomes due to systematic differences between treatment groups in terms of prognostic factors-this is known as channelling bias, which can impact pharmacoepidemiological studies of safety and effectiveness. ${ }^{23}$

\section{Aim}

The aim of this study is to provide real-world evidence on the early persistence of OAC use for stroke prevention in people with NVAF in a period where there were four OACs available for this indication. In this paper, we describe the characteristics of people with NVAF who are newly prescribed OACs for stroke prevention, estimate OAC persistence rates and compare the persistence rates of the newly prescribed OACs in routine clinical practice in the UK.

\section{METHODS}

\section{Study design}

This was a cohort study of patients with NVAF who were newly initiated an OAC during routine clinical practice in the UK identified with retrospective data from the Clinical Practice Research Datalink (CPRD). The CPRD contains anonymised medical records for patients registered at general practices in the UK (currently around $7 \%$ of the UK population). ${ }^{24}$ It contains information recorded during routine clinical practice, for example, medical diagnoses, prescriptions issued and diagnostic tests. This study was approved by the Independent Scientific Advisory Committee (protocol number 14_215R) and is registered on ClinicalTrials.gov (identifier NCT02488421).

\section{Study population}

We identified adults with NVAF who newly initiated an OAC during the study period 1 December 2012 to 31 October 2014. During this period, there were four OACs available for stroke prevention in NVAF- the traditionally prescribed VKAs and three NOACs dabigatran, rivaroxaban and apixaban. Apixaban was licenced for this indication at the beginning of the study period. Since apixaban could not have been prescribed before the study period, patients prescribed apixaban would be newly prescribed. Patients in the rivaroxaban, dabigatran and VKA cohorts were therefore also required to be newly prescribed. For each newly prescribed OAC, we defined the index date at the start of the newly prescribed OAC in the study period. All patients were aged 18 years or older at the index date and had at least 12 months of computerised medical records prior to this date. The patients and practices met CPRD's research quality. $^{24}$

We excluded patients who did not have a record of an $\mathrm{AF}$ diagnosis on or before index date and patients who had a record for a valvular condition (moderate-severe mitral stenosis and prosthetic heart valves) on or before to index date. We excluded patients with a prescribing history of the index OAC before the index date as the index $\mathrm{OAC}$ was not new in this instance.

Among the patients who met these criteria, the study population was categorised into those who were OAC naive, that is, had no history of any OAC prior to the index date, and those who were OAC experienced (ie, had history of a different OAC prior to index date). The main group of interest examined in this study are OAC naive patients and the results presented in this paper 
focus on this subpopulation. Within these subsets of the study population, patients were further allocated to an OAC cohort determined by the newly prescribed OAC on the index date. Time varying exposures were allowed for; patients could be in more than one OAC cohort if they were newly prescribed more than one OAC over the study period (figure 1). ${ }^{25}$

\section{Definition of OAC treatment persistence}

We grouped together consecutive prescriptions of the same OAC for each patient from the first record in their history to the end of follow-up (ie, earliest of end of study period, last data collection, leaving the practice or death) to form treatment lines. We estimated the duration of each prescription to assign prescription end dates. We used duration if provided in the data, else, we calculated duration based on quantity and daily dose. Where this information was not available, we imputed the overall median duration for that OAC.

We defined a 'discontinuation period' as twice the median duration of a single prescription: apixaban, rivaroxaban and VKA had a median duration of 28 days, dabigatran 30 days, giving discontinuation periods of 56 days and 60 days, respectively. As per Zalesak et al, ${ }^{10}$ this is a clinically relevant length of time, in which a patient is expected to fill the next prescription should they choose to continue treatment. We measured the gap between the end of each prescription and the date of the next prescription and defined a treatment line as discontinued if:

- The gap was more than the length of the discontinuation period;
- There were more than the length of the discontinuation period between the end of the treatment line and the end of follow-up.

A switch occurred if a different OAC was introduced into the regimen or within the discontinuation period following the end of the treatment line. We extended VKA treatment lines to include international normalised ratio (INR) records (as INR is only recorded if being treated with VKA) by assigning INR records with the median duration observed for prescriptions of VKA. In addition, for every VKA treatment line, a 30-day grace period was added to the end of the treatment line to allow for modifications in the weekly dose not reflected in the original prescription.

For the index treatment line, we defined it as persistent if there was no regimen change (ie, discontinuation or switch). Persistence was not assessed for treatment lines with an insufficient amount of follow-up data (length of discontinuation period or less ie, 56 days or less for apixaban, rivaroxaban and VKA or 60 days or less for dabigatran).

\section{Statistical analyses}

Demographic (age, gender and country) and clinical characteristics (time since AF diagnosis, history of stroke risk factors, $\mathrm{CHA}_{2} \mathrm{DS}_{2} \mathrm{VASc}$ score (where $\geq 2$ indicates high stroke risk), bleeding events, HAS-BLED score (where $\geq 3$ indicates high bleeding risk), co-medication use) were described in the OAC naive and OAC experienced groups and within each OAC cohort.

In patients where persistence was assessed, we calculated the proportion of patients who were persistent over the course of follow-up; of those who were
Figure 1 Illustration of newly prescribed OAC scenariosexample of VKA, rivaroxaban and apixaban. Arrows indicate OACs that are included in the study. OAC, oral anticoagulants; VKA, vitamin $\mathrm{K}$ antagonists.

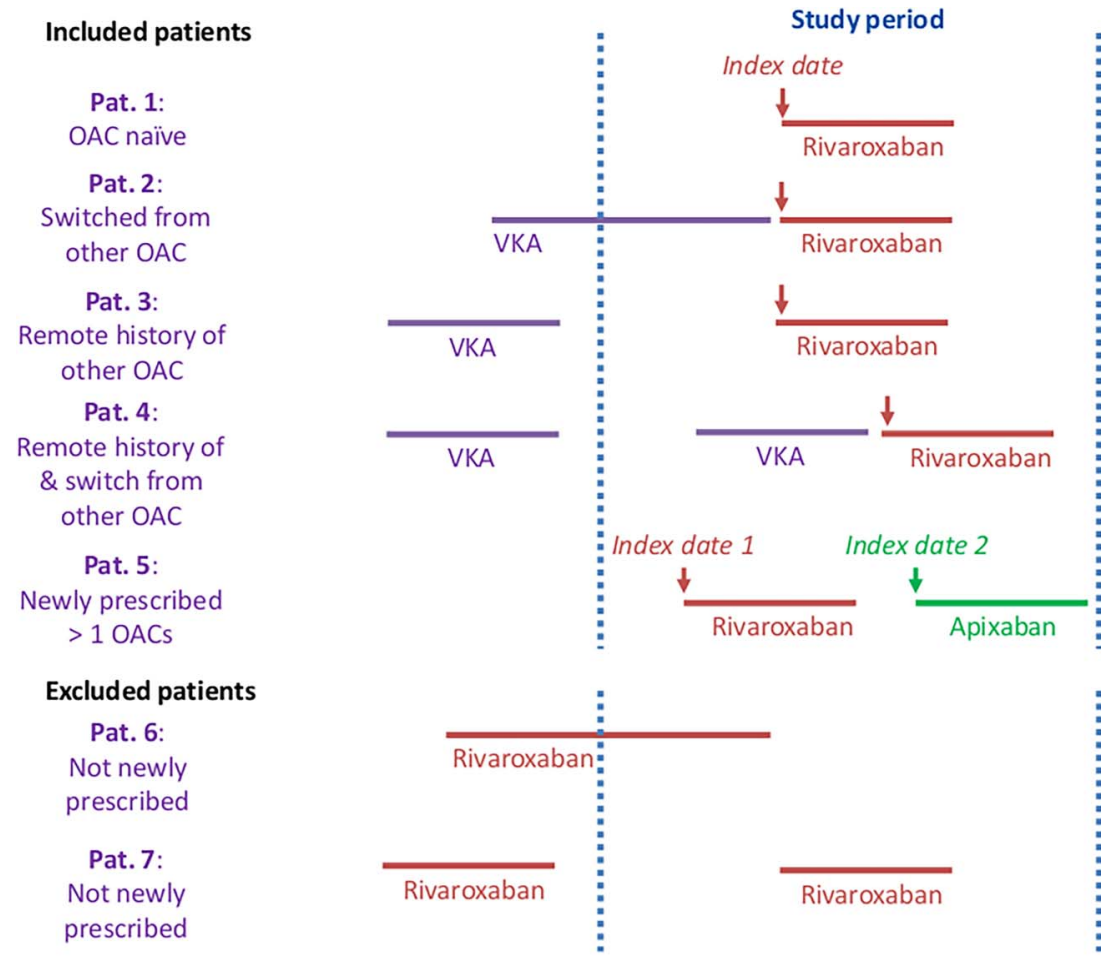


non-persistent, we calculated the proportion of patients who discontinued and switched therapy. We calculated cumulative incidence rates of persistence (accounting for the competing risk of death), the number of patients at risk and the number censored over the entire follow-up period available and at specific time periods (3, 6 and 12 months) of follow-up for each OAC cohort. We presented cumulative incidence curves to illustrate the rate of non-persistence over the follow-up time in each OAC cohort.

We compared apixaban persistence with each of the other OACs using marginal Cox regression methods to model time to non-persistence over the whole of patients' follow-up. Differences in follow-up time were accounted for through non-informative censoring at the earliest of leaving the practice, last data collection or the end of study period. We also censored on death which, although death is a competing risk for non-persistence in the data, yields an unbiased estimate of the causespecific HR from Cox regression models. We reported HRs and associated 95\% CIs, showing the average effect over the course of follow-up. To assess the proportionality assumption, we examined Schoenfeld residuals. Since non-proportional hazards were observed, we performed a post hoc analysis; a time-partitioned approach to compare persistence between OAC cohorts in separate periods of follow-up. We partitioned follow-up by identifying (through the cumulative incidences) that the pattern of VKA persistence changed at 60 days. We adjusted the HRs for differences in baseline characteristics and variables of clinical interest by starting with the full model and undertaking a significance-based manual backward selection approach; variables with evidence at the 5\% level of being associated with persistence were included. The full model from which the adjusted model was derived included gender, age at index date, country (England, Wales, Scotland and Northern Ireland), smoking status (current smoker, ex-smoker and never smoked), history of stroke risk factors (stroke or transient ischaemic attack (TIA), thromboembolism, congestive heart failure, vascular disease, hypertension, diabetes), history of any bleeding, history of liver disease, concomitant therapies prescribed on or up to 3 months after the index date (parenteral anticoagulants, aspirin, other antiplatelets and non-steroidal antiinflammatory drugs). No imputation of missing data was undertaken and a complete case analysis was conducted whereby patients without a smoking status were not included in the full model.

We conducted two sensitivity analyses. Cumulative incidence rates of persistence were reanalysed using a 30-day discontinuation gap instead of 60 days. The shorter period has been used in another study, ${ }^{16}$ and this sensitivity analysis allowed us to observe the extent to which this altered the level of non-persistence. Cumulative incidence rates of non-persistence were also reanalysed without using INR records to extend the VKA treatment lines. This assumption was made to account for VKA prescribing outside of primary care; by relaxing it in the sensitivity analysis, we aimed to facilitate comparisons with other studies which have not used INR records.

All analyses were conducted in SAS V.9.4 (SAS Institute, Cary, North Carolina, USA).

\section{RESULTS}

\section{Cohort allocation}

There were 15242 adults with NVAF who were newly prescribed an OAC between 1 December 2012 and 31 October 2014, of which 13089 (85.9\%) were OAC naïve. Within the OAC naïve group, VKAs were the dominant OAC, newly prescribed to $78.1 \%$ of the study population $(\mathrm{n}=10218)$. This was followed by rivaroxaban $(12.1 \%$, $\mathrm{n}=1589)$, dabigatran $(5.7 \%, \mathrm{n}=741)$ and apixaban $(4.1 \%$, $\mathrm{n}=541)$. There were 2978 index exposures among 2861 patients where other OACs had been used before that is, OAC experienced. In this group, rivaroxaban was dominant $(52.9 \%, \mathrm{n}=1576)$ followed by dabigatran $(27.3 \%$, $\mathrm{n}=814)$, apixaban $(16.2 \%, \mathrm{n}=482)$ and VKA $(3.6 \%$, $\mathrm{n}=106$ ).

In the OAC naïve group, the median time from $\mathrm{AF}$ diagnosis to OAC initiation varied slightly across the OAC cohorts-just over a month in the VKA cohort (1.3, IQR 0.4 to 7.9$), 2$ months in the apixaban cohort (2.0, IQR 0.5 to 21.2) and two and a half months in the rivaroxaban (2.6, IQR 0.5 to 35.5) and dabigatran (2.6, IQR 0.5 to 34.6) cohorts (table 1). New use of VKA declined over time, while an increasing proportion of patients were started on rivaroxaban or apixaban during the study period. Median follow-up time from index date was 4 months in apixaban patients (IQR 2.1 to 7.3), 5.8 months in rivaroxaban patients (IQR 2.6 to 11.0), 9.4 months in dabigatran patients (IQR 4.2 to 15.6 ) and 10.3 months in VKA patients (IQR 5.0 to 15.9).

\section{Characteristics}

Slightly more than half of the OAC naive patients were male $(55.4 \%, \mathrm{n}=7250)$ (table 1$)$. The majority of patients starting OACs were older, with a median age at index date of 75 years (IQR 68 to 82). Age was similar across the OAC cohorts, with median age ranging from 74 years (dabigatran cohort, IQR 66 to 81 ) to 77 years (rivaroxaban cohort, IQR 70 to 83).

Stroke risk was high among all OAC cohorts, ranging from $80.2 \%$ with a $\mathrm{CHA}_{2} \mathrm{DS}_{2}$ VASc score $\geq 2$ in the dabigatran cohort to $88.4 \%$ in the apixaban and rivaroxaban cohorts (table 1 and figure 2). A history of stroke/TIA was more common among NOAC users $(21.1 \%$ overall), than VKA users $(15.9 \%)$ and was the highest in the apixaban cohort $(23.7 \%$ ) (table 1 and figure 3). A HAS-BLED score of $\geq 3$, representing a high risk of bleeding, was observed in $\sim 75 \%$ of the overall population, from $72.1 \%$ in the dabigatran cohort to $76.7 \%$ in the rivaroxaban cohort (table 1 and figure 2). History of any bleeding events was common in $27.5 \%$ of the 
Table 1 Baseline characteristics of OAC naïve patients

\begin{tabular}{|c|c|c|c|c|c|c|c|c|c|c|}
\hline & \multirow{2}{*}{\multicolumn{2}{|c|}{$\begin{array}{l}\text { All study population } \\
\mathrm{N}=13089\end{array}$}} & \multicolumn{2}{|c|}{ Apixaban } & \multicolumn{2}{|c|}{ Rivaroxaban } & \multicolumn{2}{|c|}{ Dabigatran } & \multicolumn{2}{|l|}{ VKA } \\
\hline & & & $\mathrm{N}=54$ & & $\mathrm{~N}=158$ & & $\bar{N}=74$ & & $\mathrm{~N}=10$ & \\
\hline \multicolumn{11}{|l|}{ Gender (n, \%) } \\
\hline Male & 7250 & $55.4 \%$ & 288 & $53.2 \%$ & 882 & $55.5 \%$ & 457 & $61.7 \%$ & 5623 & $55.0 \%$ \\
\hline Female & 5839 & $44.6 \%$ & 253 & $46.8 \%$ & 707 & $44.5 \%$ & 284 & $38.3 \%$ & 4595 & $45.0 \%$ \\
\hline \multicolumn{11}{|l|}{ Country (n, \%) } \\
\hline England & 9660 & $73.8 \%$ & 328 & $60.6 \%$ & 1160 & $73.0 \%$ & 614 & $82.9 \%$ & 7558 & $74.0 \%$ \\
\hline Wales & 1404 & $10.7 \%$ & 40 & $7.4 \%$ & 63 & $4.0 \%$ & 57 & $7.7 \%$ & 1244 & $12.2 \%$ \\
\hline Scotland & 1471 & $11.2 \%$ & 56 & $10.4 \%$ & 278 & $17.5 \%$ & 38 & $5.1 \%$ & 1099 & $10.8 \%$ \\
\hline Northern Ireland & 554 & $4.2 \%$ & 117 & $21.6 \%$ & 88 & $5.5 \%$ & 32 & $4.3 \%$ & 317 & $3.1 \%$ \\
\hline \multicolumn{11}{|l|}{ Age (years) at index date } \\
\hline Median (IQR) & \multicolumn{2}{|c|}{$75.0(68.0-82.0)$} & \multicolumn{2}{|c|}{$75.0(68.0-83.0)$} & \multicolumn{2}{|c|}{$77.0(70.0-83.0)$} & \multicolumn{2}{|c|}{$74.0(66.0-81.0)$} & \multicolumn{2}{|c|}{$75.0(68.0-82.0)$} \\
\hline \multicolumn{11}{|c|}{ Time (months) between AF diagnosis and index date } \\
\hline Median (IQR) & \multicolumn{2}{|c|}{$1.4(0.4-12.2)$} & \multicolumn{2}{|c|}{$2.0(0.5-21.2)$} & \multicolumn{2}{|c|}{$2.6(0.5-35.5)$} & \multicolumn{2}{|c|}{$2.6(0.5-34.6)$} & \multicolumn{2}{|c|}{$1.3(0.4-7.9)$} \\
\hline \multicolumn{11}{|l|}{ History of stroke risk factors (n, \%) } \\
\hline Stroke or transient ischaemic attack & 2230 & $17.0 \%$ & 128 & $23.7 \%$ & 326 & $20.5 \%$ & 152 & $20.5 \%$ & 1624 & $15.9 \%$ \\
\hline Congestive heart failure & 1550 & $11.8 \%$ & 56 & $10.4 \%$ & 173 & $10.9 \%$ & 58 & $7.8 \%$ & 1263 & $12.4 \%$ \\
\hline Vascular disease & 3532 & $27.0 \%$ & 124 & $22.9 \%$ & 415 & $26.1 \%$ & 169 & $22.8 \%$ & 2824 & $27.6 \%$ \\
\hline Hypertension & 8168 & $62.4 \%$ & 322 & $59.5 \%$ & 1031 & $64.9 \%$ & 423 & $57.1 \%$ & 6392 & $62.6 \%$ \\
\hline Diabetes & 2469 & $18.9 \%$ & 96 & $17.7 \%$ & 302 & $19.0 \%$ & 121 & $16.3 \%$ & 1950 & $19.1 \%$ \\
\hline \multicolumn{11}{|l|}{$\mathrm{CHA}_{2} \mathrm{DS}_{2}$-VASc score at index date $(\mathrm{n}, \%)$} \\
\hline$<2$ & 1737 & $13.3 \%$ & 63 & $11.7 \%$ & 185 & $11.6 \%$ & 147 & $19.8 \%$ & 1342 & $13.1 \%$ \\
\hline$\geq 2$ & 11352 & $86.7 \%$ & 478 & $88.4 \%$ & 1404 & $88.4 \%$ & 594 & $80.2 \%$ & 8876 & $86.9 \%$ \\
\hline HAS-BLED score ${ }^{\star}$ at index date (n, \%) & & & & & & & & & & \\
\hline$<3$ & 3373 & $25.8 \%$ & 137 & $25.3 \%$ & 370 & $23.3 \%$ & 207 & $27.9 \%$ & 2659 & $26.0 \%$ \\
\hline$\geq 3$ & 9716 & $74.2 \%$ & 404 & $74.7 \%$ & 1219 & $76.7 \%$ & 534 & $72.1 \%$ & 7559 & $74.0 \%$ \\
\hline History of other events (n, \%) & & & & & & & & & & \\
\hline Gastrointestinal ulceration & 655 & $5.0 \%$ & 26 & $4.8 \%$ & 74 & $4.7 \%$ & 35 & $4.7 \%$ & 520 & $5.1 \%$ \\
\hline Gastrointestinal bleeding & 1312 & $10.0 \%$ & 65 & $12.0 \%$ & 148 & $9.3 \%$ & 64 & $8.6 \%$ & 1035 & $10.1 \%$ \\
\hline Intracranial bleeding & 110 & $0.8 \%$ & 12 & $2.2 \%$ & 18 & $1.1 \%$ & 11 & $1.5 \%$ & 69 & $0.7 \%$ \\
\hline Other bleeding $†$ & 2669 & $20.4 \%$ & 120 & $22.2 \%$ & 300 & $18.9 \%$ & 149 & $20.1 \%$ & 2100 & $20.6 \%$ \\
\hline Any bleedingt & 3594 & $27.5 \%$ & 171 & $31.6 \%$ & 413 & $26.0 \%$ & 205 & $27.7 \%$ & 2805 & $27.5 \%$ \\
\hline Concomitant therapy $\ddagger$ (n, \%) & & & & & & & & & & \\
\hline Antiplatelet & 2824 & $21.6 \%$ & 47 & $8.7 \%$ & 234 & $14.7 \%$ & 137 & $18.5 \%$ & 2406 & $23.6 \%$ \\
\hline Aspirin & 2271 & $17.4 \%$ & 36 & $6.7 \%$ & 189 & $11.9 \%$ & 111 & $15.0 \%$ & 1935 & $18.9 \%$ \\
\hline Other antiplatelet therapy§ & 740 & $5.7 \%$ & 14 & $2.6 \%$ & 66 & $4.2 \%$ & 34 & $4.6 \%$ & 626 & $6.1 \%$ \\
\hline Antiarrhythmic & 925 & $7.1 \%$ & 43 & $8.0 \%$ & 111 & $7.0 \%$ & 67 & $9.0 \%$ & 704 & $6.9 \%$ \\
\hline Beta-blocker & 8538 & $65.2 \%$ & 343 & $63.4 \%$ & 986 & $62.1 \%$ & 456 & $61.5 \%$ & 6753 & $66.1 \%$ \\
\hline Non-steroidal anti-inflammatory drugs & 309 & $2.4 \%$ & 21 & $3.9 \%$ & 42 & $2.6 \%$ & 31 & $4.2 \%$ & 215 & $2.1 \%$ \\
\hline Statin & 6759 & $51.6 \%$ & 263 & $48.6 \%$ & 824 & $51.9 \%$ & 358 & $48.3 \%$ & 5314 & $52.0 \%$ \\
\hline Antidiabetic agent & 1564 & $12.0 \%$ & 55 & $10.2 \%$ & 195 & $12.3 \%$ & 80 & $10.8 \%$ & 1234 & $12.1 \%$ \\
\hline Antihypertensive agent & 11733 & $89.6 \%$ & 461 & $85.2 \%$ & 1396 & $87.9 \%$ & 648 & $87.5 \%$ & 9228 & $90.3 \%$ \\
\hline Proton pump inhibitor & 4693 & $35.9 \%$ & 195 & $36.0 \%$ & 570 & $35.9 \%$ & 245 & $33.1 \%$ & 3683 & $36.0 \%$ \\
\hline Selective serotonin reuptake inhibitor & 983 & $7.5 \%$ & 38 & $7.0 \%$ & 133 & $8.4 \%$ & 51 & $6.9 \%$ & 761 & $7.5 \%$ \\
\hline Anticonvulsant enzymatic inducer & 122 & $0.9 \%$ & 5 & $0.9 \%$ & 18 & $1.1 \%$ & 6 & $0.8 \%$ & 93 & $0.9 \%$ \\
\hline $\begin{array}{l}\text { Please note the following characteristi } \\
(n=161) \text {, rifampicin }(n=1) \text { and cytochro } \\
\text { *Labile international normalised ratio is } \\
\text { score therefore ranges from } 0 \text { to } 8 \text {. } \\
\text { tOther bleeding includes intraocular, } \\
\text { fConcomitant therapy: prescribed on } \\
\text { §Other antiplatelet therapy includes ab } \\
\text { CPRD, Clinical Practice Research Dat }\end{array}$ & $\begin{array}{l}\text { ot presen } \\
0 \text { inhibito } \\
\text { compone } \\
\text { al, urinar } \\
\text { te or with } \\
\text {, clopidos } \\
\text { AC, oral a }\end{array}$ & $\begin{array}{l}\text { to low } n \\
\text { e HAS-B } \\
\text { articular } \\
\text { nths afte } \\
\text { yridamol } \\
\text { gulants. }\end{array}$ & $\begin{array}{l}(<5) \text { it } \\
\text { ore bu } \\
\text { bleec } \\
\text { date. } \\
\text { grel, } \mathrm{t}\end{array}$ & $\begin{array}{l}\text { more of } \\
\text { tinclude } \\
\text { ny bleed } \\
\text { r, ticlopic }\end{array}$ & $\begin{array}{l}\text { C cohor } \\
\text { re is in } \\
\text { des ga } \\
\text { tirofiba }\end{array}$ & $\begin{array}{l}\text { nboemb } \\
\text { e interna } \\
\text { tinal, int }\end{array}$ & $\begin{array}{l}=38 \text { ), } \\
\text { ormal } \\
\text { and }\end{array}$ & $\begin{array}{l}\text { ease }(n= \\
\text { recordi } \\
\text { eding. }\end{array}$ & $\begin{array}{l}\text { nteral } \\
\text { RD. Th }\end{array}$ & $\begin{array}{l}\text { ulants } \\
\text { BLED }\end{array}$ \\
\hline
\end{tabular}


Figure 2 Distribution of $\mathrm{CHA}_{2} \mathrm{DS}_{2}$-VASc and HAS-BLED scores among $\mathrm{OAC}$ naïve patients. OAC, oral anticoagulants.
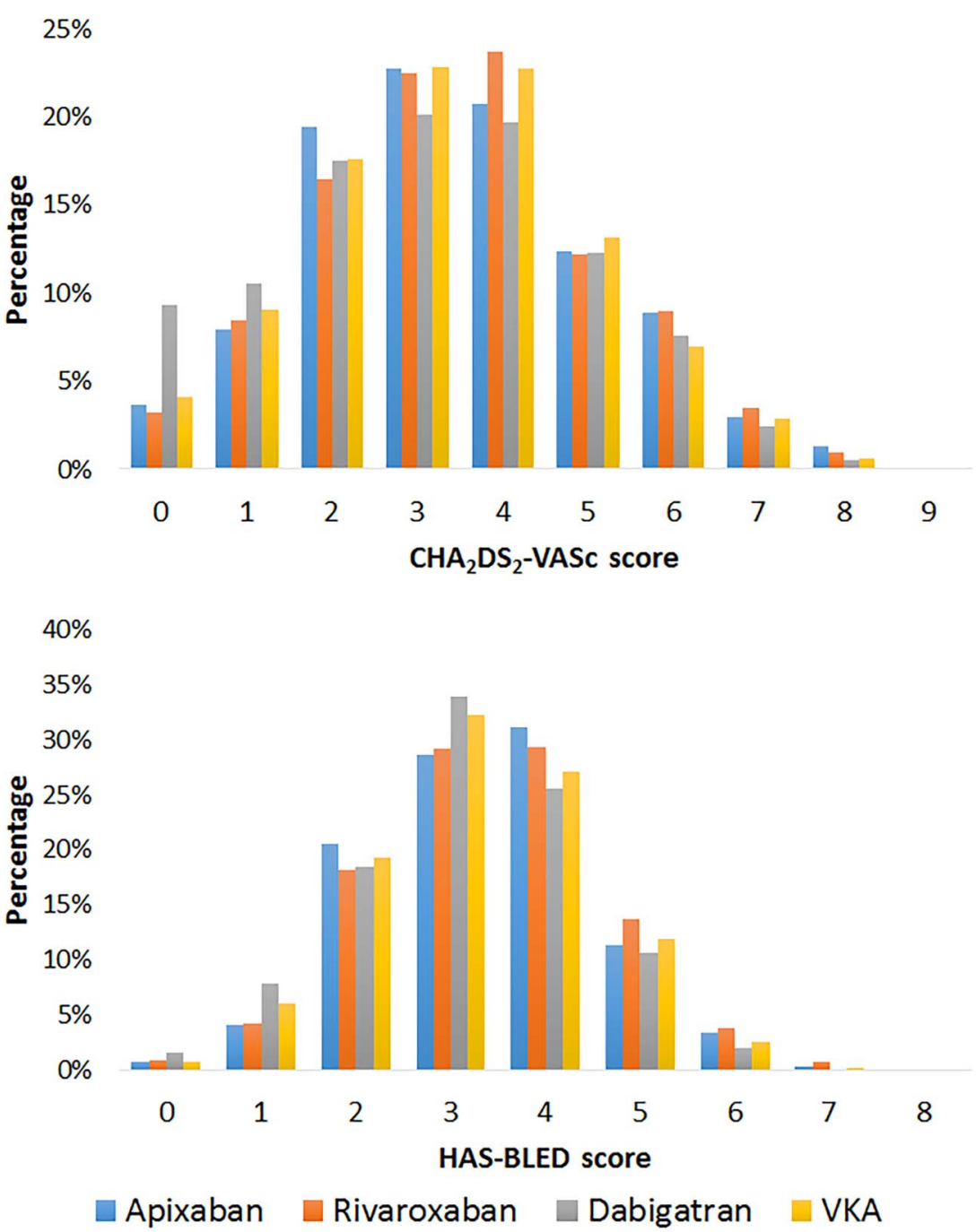

population and the highest in the apixaban cohort than other OAC cohorts; $31.6 \%$ had a gastrointestinal, intracranial or other bleeding before the index date compared with $27.5 \%$ of the VKA cohort, $27.7 \%$ of the dabigatran cohort and $26.0 \%$ of the rivaroxaban cohort (table 1 and figure 3). Concomitant therapy (prescribed on index date or within 3 months after index date) with antiplatelets was higher in the VKA cohort than the other OAC cohorts-23.6\% were also prescribed antiplatelet therapy in the VKA group, compared to $18.5 \%$, $14.7 \%$ and $8.7 \%$ in the dabigatran, rivaroxaban and apixaban groups, respectively (table 1).

The demographic characteristics of patients in the OAC experienced group (ie, patients not naïve at index date) were similar to that of the OAC naive group. However, the median time since AF diagnosis was more varied between the $\mathrm{OAC}$ cohorts than in the $\mathrm{OAC}$ naive group: VKA 0.5 months (IQR 0.1 to 1.6), dabigatran 3.4 months (IQR 1.0 to 7.5 ), rivaroxaban 4.5 months (IQR 1.5 to 9.1) and apixaban 3.7 months (IQR 1.2 to 7.7; table 2). A history of some stroke risk factors were more common in the OAC experienced group than the OAC naïve group, namely stroke/TIA (overall $27.3 \%$ vs
$17.0 \%$, respectively), congestive heart failure (overall $20.1 \%$ vs $11.8 \%$, respectively) and vascular disease (overall $30.4 \%$ vs $27.0 \%$, respectively; tables 1 and 2). Patients in the OAC experienced group also had a higher prevalence of bleeding-related events (gastrointestinal ulceration, gastrointestinal bleeding, intracranial bleeding, other bleeding, any bleeding and liver disease) in their history compared to the OAC naïve group (table 2).

\section{Persistence}

Of the 13089 OAC naïve patients, persistence was assessed for 11657 patients $(89.1 \%$ ) (9303 VKA, 1275 rivaroxaban, 656 dabigatran and 413 apixaban) who had a sufficient amount of follow-up (ie, more than the length of the discontinuation period between the index date and the end of follow-up). Overall persistence at the end of follow-up was $70.6 \%$ (95\% CI $68.9 \%$ to $72.3 \%$ ) among VKA patients, $62.5 \%$ (95\% CI $57.5 \%$ to $67.6 \%$ ) among dabigatran, $67.6 \%$ (95\% CI $62.9 \%$ to $72.2 \%)$ among rivaroxaban and $82.8 \%$ (95\% CI $76.8 \%$ to $87.9 \%$ ) among apixaban patients (table 3). Around two-thirds of non-persistence was owing to 
Figure 3 History of stroke risk factors and bleeding events among OAC naïve patients. ๆOther bleeding includes intraocular, pericardial, urinary, intra-articular and lung bleedings. Any bleeding includes gastrointestinal, intracranial and other bleeding.

$\mathrm{GI}$, gastrointestinal; OAC, oral anticoagulants; TIA, transient ischaemic attack.

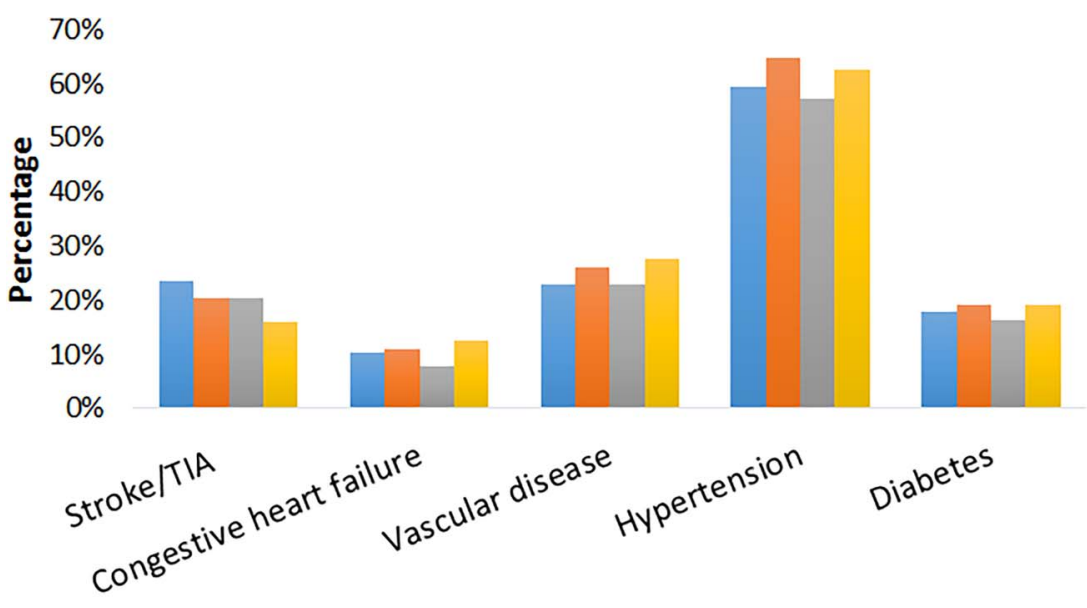

History of stroke risk factors

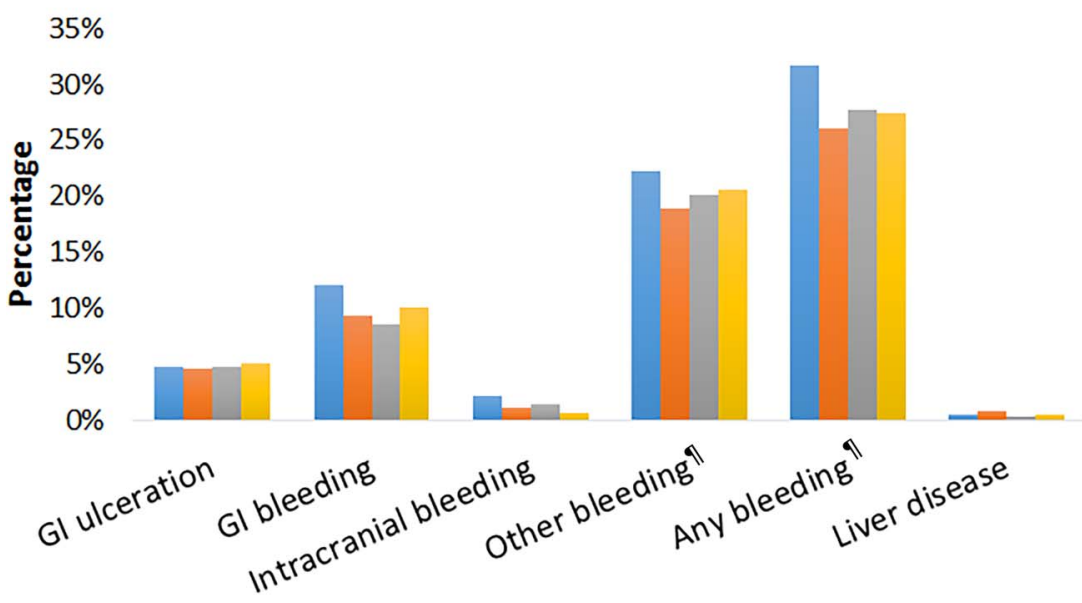

History of other events

Apixaban $\square$ Rivaroxaban $\square$ Dabigatran $\square$ VKA discontinuation of therapy and one-third was owing to switch to another OAC.

The pattern of persistence changed over the course of treatment (table 3 and figure 4). At 3 months' follow-up, persistence was high across all OAC cohorts ranging from $84.1 \%(95 \%$ CI $81.2 \%$ to $86.8 \%)$ in dabigatran users to $93.4 \%$ (95\% CI $93.4 \%$ to $94.4 \%$ ) in VKA users. At 6 months, the pattern changed with apixaban users having the highest rate of persistence (apixaban $88.2 \%$ (95\% CI $84.5 \%$ to $91.3 \%$ ); VKA $87.0 \%$ (95\% CI $86.2 \%$ to $87.7 \%)$; rivaroxaban $80.7 \% \quad(95 \%$ CI $78.4 \%$ to $83.0 \%)$; dabigatran $74.2 \%$ (95\% CI $70.6 \%$ to $77.6 \%)$ ). Persistence remained highest with apixaban at 12 months $(82.8 \%, 95 \%$ CI $76.8 \%$ to $87.9 \%)$ followed by VKA $(77.8 \%, 95 \%$ CI $76.8 \%$ to $78.7 \%)$, rivaroxaban $(73.1 \%, 95 \%$ CI $70.0 \%$ to $76.2 \%)$ and was the poorest in dabigatran users $(66.7 \%, 95 \%$ CI $62.6 \%$ to $70.7 \%)$ (table 3). However, it should be noted that the number of patients assessed at 12 months was particularly low in the apixaban cohort $(n=70)$ compared to the other OACs (rivaroxaban $\mathrm{n}=493$, dabigatran $\mathrm{n}=377$, VKA $\mathrm{n}=4979$ ).
Adjusted analyses over the whole of follow-up indicated that, on average, non-persistence was comparable between VKA and apixaban (HR 0.92, 95\% CI 0.68 to 1.23) but more likely with dabigatran and rivaroxaban than apixaban (HR 1.67, 95\% CI 1.20 to 2.32 and HR $1.41,95 \%$ CI 1.02 to 1.93 , respectively). Using the timepartitioned approach and adjusted model, we observed that in the first 2 months of treatment VKA patients were less likely to be non-persistent than apixaban patients (HR $0.33,95 \%$ CI 0.22 to 0.48 ) and dabigatran patients were more likely to be non-persistent than apixaban patients (HR $1.65,95 \%$ CI 1.08 to 2.52 ). There was a borderline statistically significant difference between rivaroxaban and apixaban persistence (HR 1.49, 95\% CI 1.00 to 2.22) (table 4). Those on VKA became more likely to be non-persistent than apixaban patients after the first 2 months of treatment (HR $1.70,95 \%$ CI 1.08 to 2.66) and patients on dabigatran were twice as likely to be nonpersistent than patients on apixaban (HR 2.10, 95\% CI 1.30 to 3.41). There was no evidence of a difference between rivaroxaban and apixaban persistence (HR 1.58, $95 \%$ CI 0.98 to 2.55 ) after 2 months of treatment. 


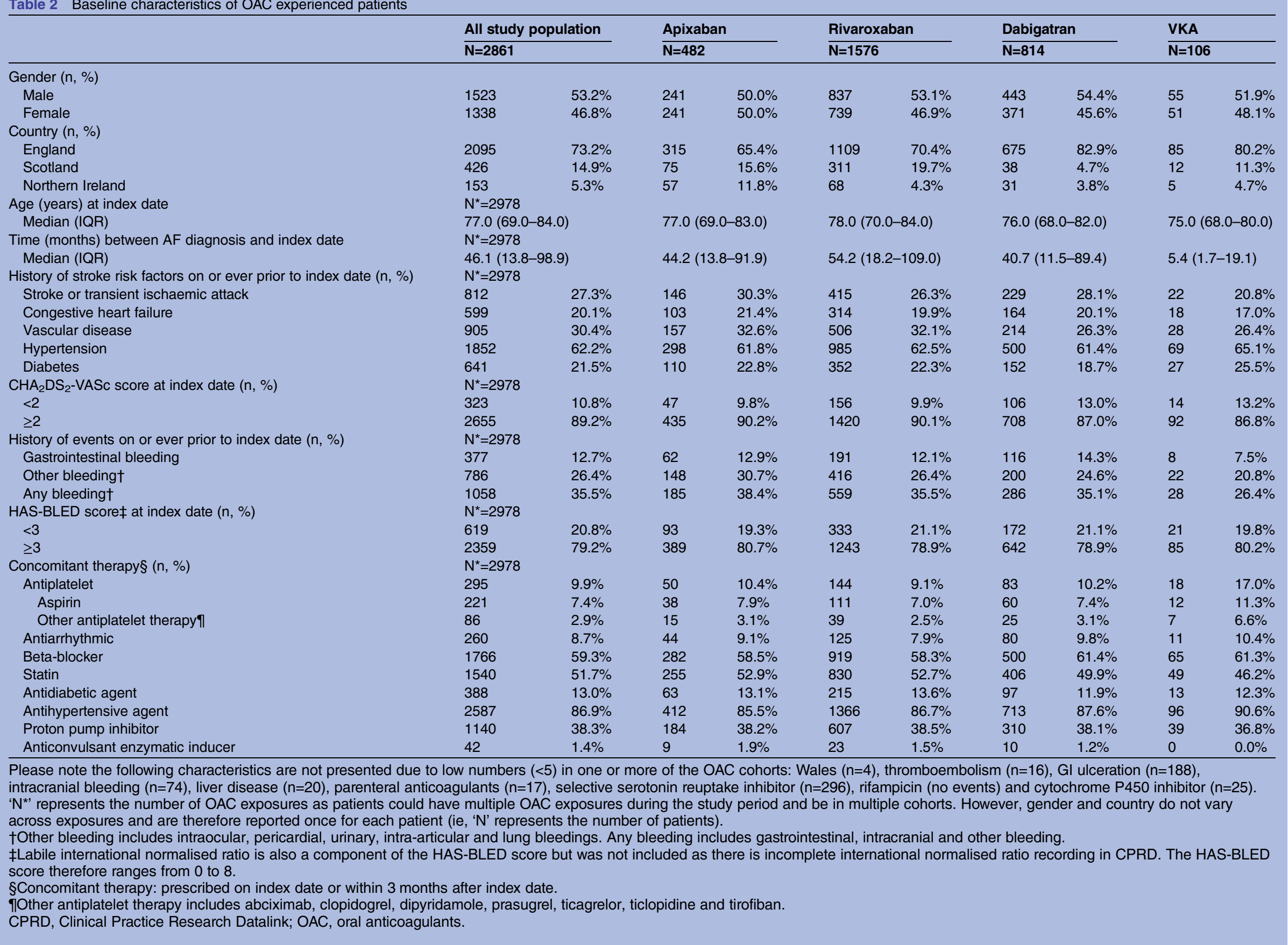


Table 3 Persistence rates of OACs among OAC naïve patients

\begin{tabular}{|c|c|c|c|c|c|c|c|c|}
\hline & \multicolumn{2}{|c|}{ Apixaban } & \multicolumn{2}{|c|}{ Rivaroxaban } & \multicolumn{2}{|c|}{ Dabigatran } & \multicolumn{2}{|l|}{ VKA } \\
\hline & \multicolumn{2}{|c|}{$\mathrm{N}=413$} & \multicolumn{2}{|c|}{$\mathrm{N}=1275$} & \multicolumn{2}{|c|}{$\mathrm{N}=656$} & \multicolumn{2}{|c|}{$\mathrm{N}=9303$} \\
\hline \multicolumn{9}{|c|}{ Persistence of index medication by the end of follow-up (n, \%) } \\
\hline Persistent & 364 & $88.1 \%$ & 999 & $78.4 \%$ & 461 & $70.3 \%$ & 7461 & $80.2 \%$ \\
\hline Non-persistent & 49 & $11.9 \%$ & 276 & $21.7 \%$ & 195 & $29.7 \%$ & 1842 & $19.8 \%$ \\
\hline Type of change in therapy $(n, \%)$ & \multicolumn{2}{|c|}{$\mathrm{N}$ non-persistent $=49$} & \multicolumn{2}{|c|}{$\mathrm{N}$ non-persistent $=276$} & \multicolumn{2}{|c|}{ N non-persistent $=195$} & \multicolumn{2}{|c|}{ N non-persistent $=1842$} \\
\hline Discontinued therapy & 31 & $63.3 \%$ & 212 & $76.8 \%$ & 126 & $64.6 \%$ & 1367 & $74.2 \%$ \\
\hline Switched therapy & 18 & $36.7 \%$ & 64 & $23.2 \%$ & 69 & $35.4 \%$ & 475 & $25.8 \%$ \\
\hline \multicolumn{9}{|l|}{ Persistence at different time points } \\
\hline \multicolumn{9}{|l|}{ At 3 months } \\
\hline Percentage $^{*}, 95 \% \mathrm{Cl}$ & 91.5 & 88.5 to 94.0 & 86.3 & 84.3 to 88.1 & 84.1 & 81.2 to 86.8 & 93.9 & 93.4 to 94.4 \\
\hline Number of patients at risk $†$ & 297 & & 945 & & 496 & & 8121 & \\
\hline Number of patients censored $\ddagger$ & 82 & & 158 & & 57 & & 630 & \\
\hline \multicolumn{9}{|l|}{ At 6 months } \\
\hline Percentage ${ }^{*}, 95 \% \mathrm{Cl}$ & 88.2 & 84.5 to 91.3 & 80.7 & 78.4 to 83.0 & 74.2 & 70.6 to 77.6 & 87.0 & 86.2 to 87.7 \\
\hline Number of patients at risk $\dagger$ & 150 & & 603 & & 351 & & 6189 & \\
\hline Number of patients censored $\ddagger$ & 220 & & 448 & & 148 & & 2005 & \\
\hline \multicolumn{9}{|l|}{ At 12 months } \\
\hline Percentage ${ }^{*}, 95 \% \mathrm{Cl}$ & 82.8 & 76.8 to 87.9 & 73.1 & 70.0 to 76.2 & 66.7 & 62.6 to 70.7 & 77.8 & 76.8 to 78.7 \\
\hline Number of patients at risk $\dagger$ & 21 & & 227 & & 189 & & 3321 & \\
\hline Number of patients censored $\ddagger$ & 343 & & 782 & & 279 & & 4324 & \\
\hline \multicolumn{9}{|l|}{ At end of follow-up } \\
\hline Percentage $^{*}, 95 \% \mathrm{Cl}$ & 82.8 & 76.8 to 87.9 & 67.6 & 62.9 to 72.2 & 62.5 & 57.5 to 67.6 & 70.6 & 68.9 to 72.3 \\
\hline Number of patients at risk $\dagger$ & 0 & & 0 & & 0 & & 0 & \\
\hline Number of patients censored & 364 & & 999 & & 461 & & 7461 & \\
\hline
\end{tabular}

${ }^{*} 100 \%$ minus the cumulative incidence of non-persistence, accounting for the competing risk of death.

†Number of patients at who remain 'at risk' of non-persistence after the specified time point.

$\ddagger$ Number of patients censored before the specified time point due to non-persistence, leaving the database, end of the study period or death.

$\mathrm{OAC}$, oral anticoagulants.

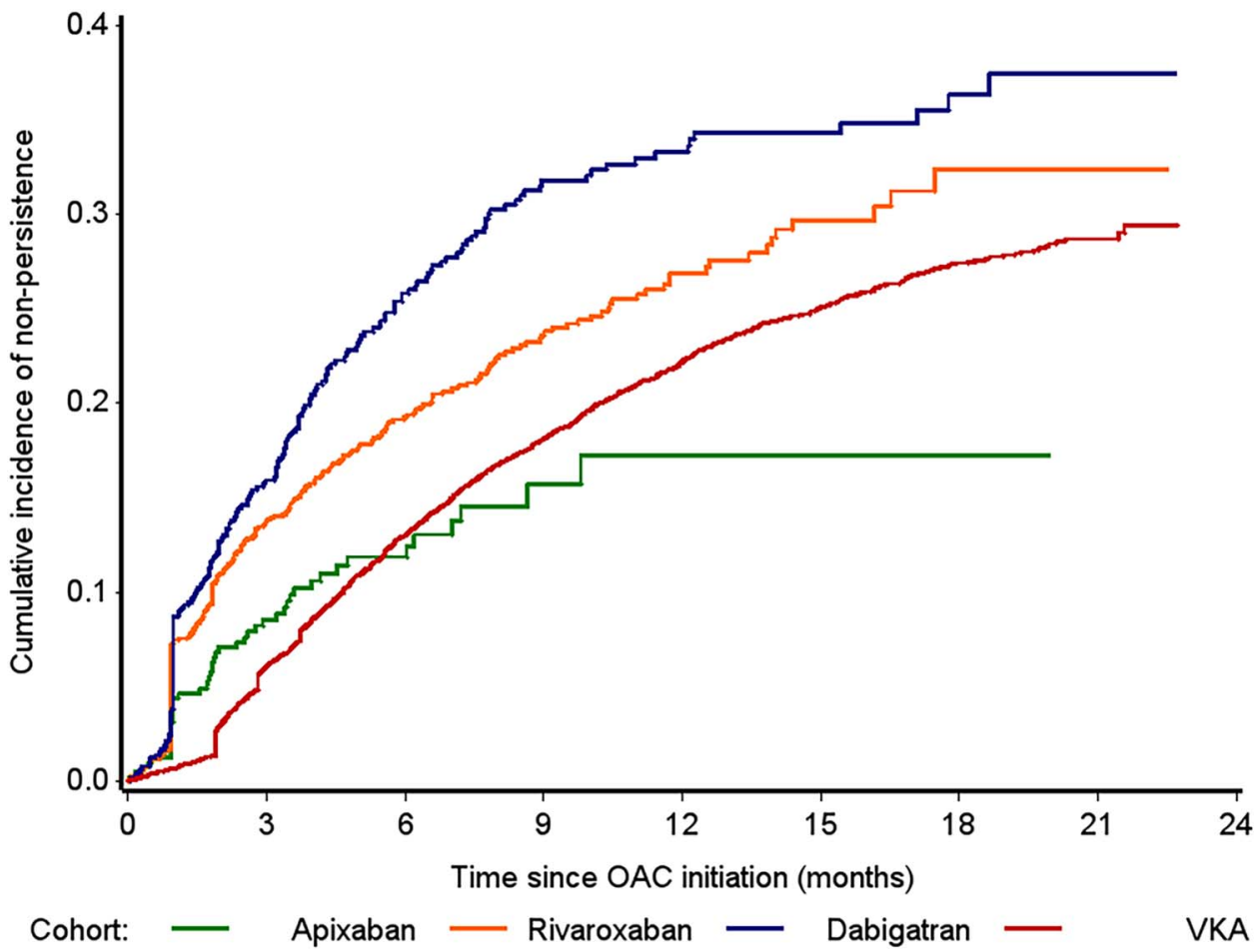

Figure 4 Cumulative incidence of non-persistence among OAC naïve patients. OAC, oral anticoagulants; VKA, vitamin K antagonists. 
Table 4 Comparison of OAC non-persistence among OAC naïve patients

\begin{tabular}{|c|c|c|c|c|}
\hline & \multirow[b]{2}{*}{ HR } & \multicolumn{2}{|l|}{$95 \% \mathrm{Cl}$} & \multirow[b]{2}{*}{ p Value } \\
\hline & & Lower & Upper & \\
\hline \multicolumn{5}{|c|}{ During the first 2 months of follow-up ( $N=11647$ ) } \\
\hline \multicolumn{5}{|c|}{ Index medication (reference category: apixaban) } \\
\hline Rivaroxaban & 1.49 & 1.00 & 2.22 & 0.052 \\
\hline Dabigatran & 1.65 & 1.08 & 2.52 & 0.022 \\
\hline VKA & 0.33 & 0.22 & 0.48 & $<0.001$ \\
\hline \multicolumn{5}{|c|}{ History of stroke risk factors (yes vs no) } \\
\hline Vascular disease & 0.81 & 0.66 & 0.99 & 0.037 \\
\hline Hypertension & 0.81 & 0.68 & 0.96 & 0.015 \\
\hline \multicolumn{5}{|c|}{ Concomitant therapy* (yes vs no) } \\
\hline Aspirin & 2.79 & 2.30 & 3.38 & $<0.001$ \\
\hline Other antiplatelet & 1.89 & 1.40 & 2.54 & $<0.001$ \\
\hline \multicolumn{5}{|c|}{ After the first 2 months of follow-up ( $N=10977)$} \\
\hline \multicolumn{5}{|c|}{ Index medication (reference category: apixaban) } \\
\hline Rivaroxaban & 1.58 & 0.98 & 2.55 & 0.059 \\
\hline Dabigatran & 2.10 & 1.30 & 3.41 & 0.003 \\
\hline VKA & 1.70 & 1.08 & 2.66 & 0.021 \\
\hline \multicolumn{5}{|l|}{ Demographics } \\
\hline Age at index date (years) & 0.99 & 0.98 & 0.99 & $<0.001$ \\
\hline \multicolumn{5}{|c|}{ Country (reference category: England) } \\
\hline Wales & 0.57 & 0.48 & 0.68 & $<0.001$ \\
\hline Scotland & 1.14 & 0.99 & 1.31 & 0.078 \\
\hline Northern Ireland & 0.84 & 0.66 & 1.07 & 0.151 \\
\hline \multicolumn{5}{|c|}{ History of stroke risk factors (yes vs no) } \\
\hline Vascular disease & 0.89 & 0.80 & 0.99 & 0.036 \\
\hline Hypertension & 0.88 & 0.80 & 0.96 & 0.005 \\
\hline \multicolumn{5}{|c|}{ Concomitant therapy* (yes vs no) } \\
\hline Parenteral anticoagulants & 1.49 & 1.07 & 2.07 & 0.020 \\
\hline Aspirin & 1.38 & 1.23 & 1.56 & $<0.001$ \\
\hline Other antiplatelet & 1.57 & 1.31 & 1.87 & $<0.001$ \\
\hline
\end{tabular}

When the analysis was expanded to include NOAC patients who were not naive to therapy $(\mathrm{N}=14063)$, the comparative likelihood of non-persistence was similar to that observed in the naive group. Overall, rivaroxaban and dabigatran users remained more likely to be nonpersistent than apixaban users (HR 1.26, 95\% CI 1.02 to 1.55 and HR $1.68,95 \%$ CI 1.35 to 2.09 respectively). In the adjusted partitioned analyses, non-persistence was less likely in VKA patients (HR $0.28,95 \%$ CI 0.21 to 0.37 ) and more likely among dabigatran users (HR 1.56, $95 \%$ CI 1.20 to 2.03 ) compared to apixaban in the first 2 months of follow-up (table 5). After the first 2 months, non-persistence was higher in VKA, dabigatran and rivaroxaban users compared to apixaban (HR 1.81, 95\% CI 1.30 to 2.53 ; HR $2.32,95 \%$ CI 1.63 to 3.31 ; HR 1.69 , $95 \%$ CI 1.19 to 2.39 respectively).

In the sensitivity analyses, using a 30-day discontinuation period lowered the persistence rates as expected: for example, apixaban persistence at 12 months fell from $82.8 \%$ (95\% CI $76.8 \%$ to $87.9 \%$ ) to $67.8 \%$ (95\% CI $60.0 \%$ to $75.3 \%$ ); rivaroxaban from $73.1 \%$ (95\% CI $70.0 \%$ to $76.2 \%$ ) to $61.9 \%$ ( $95 \%$ CI $58.4 \%$ to $65.3 \%$ ); dabigatran from $66.7 \%$ (95\% CI $62.6 \%$ to $70.7 \%$ ) to
$53.0 \%$ (95\% CI $48.8 \%$ to $57.4 \%$ ); and VKA from $77.8 \%$ (95\% CI $76.8 \%$ to $78.7 \%$ ) to $68.4 \%$ (95\% CI $67.3 \%$ to $69.5 \%)$. The removal of INR records from VKA persistence also lowered VKA persistence: the 12-month VKA persistence changed from $77.8 \%$ (95\% CI $76.8 \%$ to $78.7 \%$ ) to $61.2 \%$ (95\% CI $60.0 \%$ to $63.4 \%$ ).

\section{DISCUSSION}

This study examined patient characteristics and persistence rates of patients with NVAF newly initiated on OACs between 1 October 2012 and 31 December 2014 in the real-world setting of routine UK clinical practice. Patients newly initiated on OACs in the study period had, overall, a high baseline risk of stroke and bleeding, which varied depending on which OAC was prescribed and whether they were new to therapy. Despite early patterns of persistence changing over time since OAC initiation, comparatively, patients prescribed apixaban showed improved persistence over rivaroxaban, dabigatran and VKAs.

This study provides real-world evidence on the early persistence of apixaban and other OACs in people with 
Table 5 Comparison of OAC non-persistence among OAC naïve and experienced patients

\begin{tabular}{|c|c|c|c|c|}
\hline & \multirow[b]{2}{*}{ HR } & \multicolumn{2}{|l|}{$95 \% \mathrm{Cl}$} & \multirow[b]{2}{*}{ p Value } \\
\hline & & Lower & Upper & \\
\hline \multicolumn{5}{|c|}{ During the first 2 months of follow-up ( $N=14$ 063) } \\
\hline \multicolumn{5}{|c|}{ Index medication (reference category: apixaban) } \\
\hline Rivaroxaban & 1.17 & 0.91 & 1.50 & 0.224 \\
\hline Dabigatran & 1.56 & 1.20 & 2.03 & $<0.001$ \\
\hline VKA & 0.28 & 0.21 & 0.37 & $<0.001$ \\
\hline \multicolumn{5}{|c|}{ History of stroke risk factors (yes vs no) } \\
\hline Vascular disease & 0.79 & 0.67 & 0.93 & 0.004 \\
\hline Hypertension & 0.87 & 0.75 & 1.00 & 0.042 \\
\hline OAC history (yes vs no) & 1.42 & 1.20 & 1.67 & $<0.001$ \\
\hline \multicolumn{5}{|c|}{ Concomitant therapy* (yes vs no) } \\
\hline Parenteral anticoagulants & 2.22 & 1.21 & 4.10 & 0.011 \\
\hline Aspirin & 2.75 & 2.34 & 3.22 & $<0.001$ \\
\hline Other antiplatelet & 1.93 & 1.49 & 2.50 & $<0.001$ \\
\hline \multicolumn{5}{|c|}{ After the first 2 months of follow-up ( $N=13005)$} \\
\hline \multicolumn{5}{|c|}{ Index medication (reference category: apixaban) } \\
\hline Rivaroxaban & 1.69 & 1.19 & 2.39 & 0.003 \\
\hline Dabigatran & 2.32 & 1.63 & 3.31 & $<0.001$ \\
\hline VKA & 1.81 & 1.30 & 2.53 & $<0.001$ \\
\hline \multicolumn{5}{|l|}{ Demographics } \\
\hline Age at index date (years) & 0.99 & 0.98 & 0.99 & $<0.001$ \\
\hline \multicolumn{5}{|c|}{ Country (reference category: England) } \\
\hline Wales & 0.59 & 0.50 & 0.71 & $<0.001$ \\
\hline Scotland & 1.11 & 0.97 & 1.26 & 0.133 \\
\hline Northern Ireland & 0.84 & 0.67 & 1.07 & 0.155 \\
\hline \multicolumn{5}{|c|}{ History of stroke risk factors (yes vs no) } \\
\hline Vascular disease & 0.89 & 0.80 & 0.98 & 0.022 \\
\hline Hypertension & 0.86 & 0.79 & 0.94 & 0.001 \\
\hline \multicolumn{5}{|c|}{ Concomitant therapy* (yes vs no) } \\
\hline Parenteral anticoagulants & 1.44 & 1.04 & 2.01 & 0.031 \\
\hline Aspirin & 1.39 & 1.24 & 1.56 & $<0.001$ \\
\hline Other antiplatelet & 1.52 & 1.28 & 1.81 & $<0.001$ \\
\hline
\end{tabular}

NVAF and is the first to provide real-world evidence on the comparative persistence of apixaban in NVAF in the UK.

There are several strengths to this study. The database we have used is a comprehensive, well-validated primary care database from the UK which captures a large population of patients with diagnosis of AF. ${ }^{24} 2627$ The advantage of using, specifically, a UK primary care database is twofold. First, the gatekeeper system in the UK restricts consultation with a specialist to those referred from a general practitioner (GP), thus our sample should be representative of patients with AF. Second, in the UK, it is the GP who is responsible for prescribing, thus primary care data should capture the vast majority of treatment (except for in emergency situations) allowing us to observe the treatment patterns in the data.

A further strength of this study is that the database provided information on INR tests. This allowed us to account for possible changes to dosing and prescriptions as a result of INR testing, which normally occurs outside of primary care. This extended the VKA treatment lines and we considered this approach to be conservative; this was confirmed through a sensitivity analysis which used
VKA treatment lines without INR records and grace period and resulted in an increase in VKA nonpersistence and a higher proportion of discontinuation in particular.

We used a discontinuation period of $\sim 60$ days, which is a length supported by investigations from Zalesak et $a l^{10}$ - they found over $90 \%$ of patients who filled a subsequent prescription of dabigatran or warfarin had done this within 60 days of the last prescription. A sensitivity analysis using 30 days in our study resulted in high levels of non-persistence indicating 60 days was a more plausible approach.

There are also limitations to this study. Despite the majority of prescribing in the UK being conducted through primary care, secondary care prescribing is possible and unlikely to be recorded in primary care data. For AF, in some parts of the UK, healthcare professionals are advised that treatment is started by a secondary care consultant and, continued by GPs. ${ }^{28}$ In these areas, there may be a lack of data captured on initial OAC use; however, subsequent prescriptions will be observed in the data. Overall the length of this potential 
interval between treatment initiated outside of primary care and prescriptions observed in primary care may be around a month and a half as indicated by the average time observed between AF diagnosis and OAC initiation among OAC naïve patients.

The presented results are focused on patients who are naive to OAC therapy. It should be borne in mind that patients started on a NOAC instead of a VKA may represent a different group of patients since VKA has been the usual standard of care and is cheaper to prescribe than the NOACs. Our examination of the patient characteristics across the OAC cohorts was consistent with this as we found that a slightly higher proportion of patients had a history of stroke and intracranial bleeding events in the NOAC cohorts than the VKA cohort. The use of CPRD data has enabled the assessment of these characteristics and the adjustment of a wide range of variables when comparing persistence. However, there are limitations to using primary care data such as missing data (eg, smoking status) which can contribute to residual confounding, a problem which can affect all observational studies and is likely to be present in this study. Also, lack of detail on diagnoses, for example, bleeding resulting in hospitalisation and minor bleeds are unlikely to be uniformly and specifically coded throughout GP practices.

Treatment persistence is commonly studied using routinely collected data, ${ }^{21}{ }^{22}{ }^{29}$ such as those used in this study. The strengths we have mentioned-large samples, information on comorbidities and prescriptions-have to be balanced with the overall difficulties in estimating persistence with this data. Assumptions have to be made that patients take their prescribed drugs, and in studies like ours, how often the patient is taking them or the how long the prescription lasts. The point of discontinuation is also not exact in these studies; rather it is inferred by the date on which a prescription was due to end. The time period in which non-persistence is observed (ie, the discontinuation gap in this study was 60 days) can vary between studies; however, this may reflect differences in country-specific healthcare systems and prescribing practices. For these reasons, persistence studies may vary in their design and assumptions which, despite providing valid information, can prevent the direct comparison of results. In particular, this study focuses on patients managed in UK primary care this should represent a large proportion of those with $\mathrm{AF}$ as it is common practice to be managed by the GP for chronic health conditions, but it is possible that the inferences drawn from this study are specific to this setting.

There have been few other studies which have examined persistence of OAC use in NVAF. Two studies have assessed persistence in active research settings. First, Beyer-Westendorf et al examined rivaroxaban persistence in participants of a non-interventional NOAC registry in Dresden, Germany. They observed that $85.9 \%$ (95\% CI $83.3 \%$ to $88.1 \%$ ) of participants were persistent with rivaroxaban at 12 months higher than in our study $(73.1 \%$ (95\% CI $70.0 \%$ to $76.2 \%)) .{ }^{16}$ However, the registry included patients with deep venous thrombosis and pulmonary embolism, where rivaroxaban is commonly used as short-term treatment. The elevated persistence may therefore be due to this mixed patient population as well as higher participation and, potentially, persistence in the registry compared with studies of existing real-world data. Second, early clinical trial results from The Assessment of an Education and Guidance Programme for Eliquis Adherence in Non-Valvular Atrial Fibrillation (AEGEAN) study observed a 6 months persistence rate of $90.5 \%$ among apixaban users. ${ }^{30}$

Few other studies have examined persistence to OACs using routinely collected data such as that used in our study. These data sets reflect the natural path of patient treatment and therefore provide a more 'real-world' insight into OAC persistence. In the US, Zalesak et $a l^{10}$ conducted a study of persistence with dabigatran and warfarin using US claims data and found similar rates of persistence for dabigatran users at 12 months: $63.3 \%$ compared to $66.7 \%$ in our study. However, persistence in VKA patients at 12 months was much lower in the US$38.8 \%$ compared to $77.8 \%$ in our study. Claims data do not include INR test results VKA dose adjustment arises from INR testing therefore claims data potentially underestimates the duration of VKA prescriptions.

Little is known on apixaban persistence, in particular real-world evidence is limited due to apixaban having only recently been licenced for this indication. In Sweden, regional claims data revealed similar rates of persistence at 12 months for apixaban $(85.9 \%$ (95\% CI $81.8 \%$ to $90.1 \%$ )) vs $82.8 \%$ (95\% CI $76.8 \%$ to $87.9 \%$ ) in our study) and rivaroxaban (77.4\% (95\% CI $74.6 \%$ to $80.2 \%$ ) vs $73.1 \%$ (95\% CI $70.0 \%$ to $76.2 \%$ ) in our study) but higher estimates for VKA $(85.0 \%$ (95\% CI $84.2 \%$ to $85.9 \%$ ) vs $77.8 \%$ (95\% CI $76.8 \%$ to $78.7 \%)$ ), and dabigatran $(74.4 \%$ (95\% CI $72.3 \%$ to $76.5 \%)$ vs $(66.7 \%$ (95\% CI $62.6 \%$ to $70.7 \%)$ ). ${ }^{21}$ This may be explained by methodological differences in defining drug persistence - while we used a prescription duration-based method, Forslund et al based persistence on the presence of prescription claims in six monthly intervals. They concluded better persistence with VKA and apixaban than rivaroxaban and dabigatran; however, this was based on logistic regression rather than time to event analysis and therefore is unable to infer on changes to persistence over time. Early results from a US claims data study also found better persistence with apixaban. ${ }^{20}$

This study revealed differences in the patients who were prescribed different OACs and further highlighted differences between OAC naive and OAC experienced patients. Particularly, patients given apixaban appeared to have more history of bleeding events and history of stroke. Furthermore, patients who were not naïve to therapy had a higher prevalence of stroke risk factors and bleeding events. The reasons for these differences cannot be elucidated from the data. Physicians may have 
a preference for NOACs in general because the recent European Society of Cardiology guidelines recommend that NOACs are preferable to VKAs. ${ }^{31}$ The transition from prescribing VKA to NOACs is likely to be slow while experience and confidence in the new therapeutic options increases, and this is reflected in the gradual uptake of apixaban over the study period observed in this study. With this recommendation, it is possible that physicians choose to switch certain VKA patients to a NOAC if they have greater comorbidities, particularly those with higher susceptibility to bleeding, as suggested by this study. The differences observed between naive and experienced patients is likely due to how long the patients had been diagnosed, which was longer in OAC experienced than naive patients. Differences between patients prescribed different OACs where the differences are associated with an outcome of interest is known as channelling bias in pharmacoepidemiology. Such bias should be considered when examining the comparative safety and efficacy of OACs in stroke prevention. ${ }^{23}$

Two key results on persistence emerged from this study. First, the changing pattern of VKA persistence, which was better than apixaban in the initial 2 months, was then poorer than apixaban in the subsequent months. Higher persistence with VKA could be expected due to the regular monitoring when starting VKA treatment, which is needed to ensure that the patient remains within therapeutic range and to establish the correct dose-this monitoring may encourage persistence. However, once settled on treatment and less frequently monitored, persistence may lapse. Another possible explanation is that patients were commonly stopping VKA treatment before the end of the first prescription, which would only be apparent in the data when the first prescription ended. Previous research has shown high non-persistence over 12 months with VKA which would support this theory; ${ }^{8}{ }^{17}$ however, there is little known on the persistence in the immediate months after initiation. Another reason could be the familiarity of the prescriber with NOACs that would facilitate an initial VKA prescription and later switch to NOACs in subsequent months. The second finding from this study is that apixaban persistence appeared better than other OACs. A common reason for stopping OAC treatment is the adverse bleeding events and clinical trials have shown lower rates in apixaban users than VKA patients. 91832 Reasons for better persistence cannot be established from this study, but longer persistence could suggest improved tolerability and safety. ${ }^{17} 33$ It should also be noted that among the pooled group of OAC naive and experienced patients, with more statistical power to detect a difference, non-persistence was more likely among rivaroxaban than apixaban after the first 2 months of treatment.

\section{Conclusions}

The study highlights key differences in the use of the OACs, and has shown early indications that apixaban users exhibit higher early persistence rates than the other available OACs currently available in the UK. A larger study with longer follow-up of apixaban users is needed to support these findings and to investigate whether there are differences in the risk of adverse outcomes between OACs which could explain differences in persistence.

Acknowledgements The authors would like to thank Dr Ángeles Alonso for her clinical input to this study.

Contributors MEJ and CL coordinated the execution of the study. MEJ, CL, SC, DE and AM participated in the design, execution and interpretation of results. MEJ and SC performed the statistical analyses. SC, MEJ and AM drafted the manuscript. All authors contributed to further drafts and approved the final manuscript.

Funding This study was funded by Bristol-Myers Squibb, Paris, France.

Competing interests $\mathrm{CL}, \mathrm{DE}$ and ER were employed by Bristol-Myers Squibb at the time of the study. MEJ, SC and AM were employed by OXON Epidemiology, which has received funding from Bristol-Myers Squibb to conduct the analysis and develop the manuscript. SK was employed by Pfizer at the time of the study.

Ethics approval This study was approved by the Independent Scientific Advisory Committee (Protocol number 14_215R).

Provenance and peer review Not commissioned; externally peer reviewed.

Data sharing statement No additional data are available.

Open Access This is an Open Access article distributed in accordance with the Creative Commons Attribution Non Commercial (CC BY-NC 4.0) license, which permits others to distribute, remix, adapt, build upon this work noncommercially, and license their derivative works on different terms, provided the original work is properly cited and the use is non-commercial. See: http:// creativecommons.org/licenses/by-nc/4.0/

\section{REFERENCES}

1. Ruigómez A, Johansson S, Wallander MA, et al. Incidence of chronic atrial fibrillation in general practice and its treatment pattern. $J$ Clin Epidemiol 2002;55:358-63.

2. Majeed A, Moser K, Carroll K. Trends in the prevalence and management of atrial fibrillation in general practice in England and Wales, 1994-1998: analysis of data from the general practice research database. Heart 2001;86:284-8.

3. DeWilde S, Carey Intramuscular, Emmas C, et al. Trends in the prevalence of diagnosed atrial fibrillation, its treatment with anticoagulation and predictors of such treatment in UK primary care. Heart 2006;92:1064-70.

4. Thrall G, Lane D, Carroll D, et al. Quality of life in patients with atrial fibrillation: a systematic review. Am J Med 2006;119:448. e1-19. http://www.amjmed.com/article/S0002-9343(05)01067-3/ abstract

5. Stewart S, Hart CL, Hole DJ, et al. A population-based study of the long-term risks associated with atrial fibrillation: 20-year follow-up of the Renfrew/Paisley study. Am J Med 2002;113:359-64.

6. Marini C, De Santis F, Sacco S, et al. Contribution of atrial fibrillation to incidence and outcome of ischemic stroke: results from a population-based study. Stroke 2005;36:1115-19.

7. Savelieva I, Camm AJ. Practical considerations for using novel oral anticoagulants in patients with atrial fibrillation. Clin Cardiol 2014;37:32-47.

8. Macedo AF, Bell J, McCarron C, et al. Determinants of oral anticoagulation control in new warfarin patients: analysis using data from Clinical Practice Research Datalink. Thromb Res 2015;136:250-60.

9. Fang MC, Go AS, Chang Y, et al. Warfarin discontinuation after starting warfarin for atrial fibrillation. Circ Cardiovasc Qual Outcomes 2010;3:624-31.

10. Zalesak M, Siu K, Francis K, et al. Higher persistence in newly diagnosed nonvalvular atrial fibrillation patients treated with dabigatran versus warfarin. Circ Cardiovasc Qual Outcomes 2013;6:567-74. 
11. de Andrés-Nogales F, Oyagüez I, Betegón-Nicolás L, et al. Status of oral anticoagulant treatment in patients with nonvalvular atrial fibrillation in Spain. REACT-AF Study. Rev Clin Esp 2015;215:73-82

12. European Medicines Agency. Summary of Product Characteristics: Lixiana 60mg Film-Coated Tablets (cited 18 September 2015). https://www.medicines.org.uk/emc/medicine/30506

13. Medicines Complete. British National Formulary September 2015: 2.8.2 Oral anticoagulants (cited 16 September 2015). https://www. medicinescomplete.com/mc/bnt/current/PHP1484-oral-anticoagulants. $\mathrm{htm}$

14. Miller CS, Grandi SM, Shimony A, et al. Meta-analysis of efficacy and safety of new oral anticoagulants (dabigatran, rivaroxaban, apixaban) versus warfarin in patients with atrial fibrillation. Am J Cardiol 2012;110:453-60.

15. Camm AJ, Pinto FJ, Hankey GJ, et al. Non-vitamin $\mathrm{K}$ antagonist oral anticoagulants and atrial fibrillation guidelines in practice: barriers to and strategies for optimal implementation. Europace 2015;17:1007-17.

16. Beyer-Westendorf J, Förster K, Ebertz F, et al. Drug persistence with rivaroxaban therapy in atrial fibrillation patients-results from the Dresden non-interventional oral anticoagulation registry. Europace 2015;17:530-8.

17. O'Brien EC, Simon DN, Allen LA, et al. Reasons for warfarin discontinuation in the Outcomes Registry for Better Informed Treatment of Atrial Fibrillation (ORBIT-AF). Am Heart $J$ 2014;168:487-94.

18. Granger $\mathrm{CB}$, Alexander $\mathrm{JH}$, McMurray JJ V, et al. Apixaban versus warfarin in patients with atrial fibrillation. $N$ Engl J Med 2011;365:981-92.

19. Connolly SJ, Ezekowitz MD, Yusuf S, et al. Dabigatran versus warfarin in patients with atrial fibrillation. $N$ Engl $J$ Med 2009;361:1139-51.

20. Pan X, Kachroo S, Liu X, et al. Real world discontinuation rates with apixaban versus warfarin, dabigatran, or rivaroxaban among atrial fibrillation patients newly initiated on anticoagulation therapy: early findings. J Am Coll Cardiol 2014;63:A415.

21. Forslund $T$, Wettermark B, Hjemdahl P. Comparison of treatment persistence with different oral anticoagulants in patients with atrial fibrillation. Eur J Clin Pharmacol 2015;72:329-38.

22. Martinez C, Katholing A, Wallenhorst C, et al. Therapy persistence in newly diagnosed non-valvular atrial fibrillation treated with warfarin or NOAC. A cohort study. Thromb Haemost 2016;115:31-9.
23. Petri $\mathrm{H}$, Urquhart J. Channeling bias in the interpretation of drug effects. Stat Med 1991;10:577-81.

24. Herrett E, Gallagher AM, Bhaskaran K, et al. Data resource profile: Clinical Practice Research Datalink (CPRD). Int J Epidemiol 2015;44:827-36.

25. Robins JM, Greenland S, Hu F-C. Estimation of the causal effect of a time-varying exposure on the marginal mean of a repeated binary outcome. J Am Stat Assoc 1999;94:687-700.

26. Herrett E, Thomas SL, Schoonen WM, et al. Validation and validity of diagnoses in the General Practice Research Database: a systematic review. Br J Clin Pharmacol 2010;69:4-14.

27. Lewis JD, Bilker WB, Weinstein RB, et al. The relationship between time since registration and measured incidence rates in the General Practice Research Database. Pharmacoepidemiol Drug Saf 2005;14:443-51.

28. Lyttelton M, Longmuir K, Smith S. Implementation of NICE TAs 249, 256 and 275. Dabigatran, Rivaroxaban and Apixaban for the prevention of stroke and systemic embolism in atrial fibrillation. 2013 (cited 18 September 2015). http://www.neneccg.nhs.uk/resources/ uploads/files/implementation-of-nice-tas-249-256-and-275dabigatran-rivaroxaban-and-apixaban-april-2013-final.pdf

29. Beyer-Westendorf J, Ehlken B, Evers T. Real-world persistence and adherence to oral anticoagulation for stroke risk reduction in patients with atrial fibrillation. Europace 2016;18:1150-7.

30. Bristol-Myers Squibb. Assessment of an Education and Guidance Programme for Eliquis Adherence in Non-Valvular Atrial Fibrillation (AEGEAN). European Society of Cardiology 2015 Congress; 2015. p. Abstract 2191. http://eurheartj.oxfordjournals.org/content/ehj/33/ 21/2719.full.pdf

31. Camm AJ, Lip GYH, De Caterina R, et al. 2012 focused update of the ESC Guidelines for the management of atrial fibrillation: an update of the 2010 ESC Guidelines for the management of atrial fibrillation. Developed with the special contribution of the European Heart Rhythm Association. Eur Heart J 2012;33:2719-47.

32. Mitchell SA, Simon TA, Raza S, et al. The efficacy and safety of oral anticoagulants in warfarin-suitable patients with nonvalvular atrial fibrillation: systematic review and meta-analysis. Clin Appl Thromb Hemost 2013;19:619-31.

33. Hylek EM, Held C, Alexander $\mathrm{JH}$, et al. Major bleeding in patients with atrial fibrillation receiving apixaban or warfarin: the ARISTOTLE Trial (Apixaban for Reduction in Stroke and Other Thromboembolic Events in Atrial Fibrillation): predictors, characteristics, and clinical outcomes. J Am Coll Cardiol 2014;63:2141-7 